\title{
A Systematic Review of Center of Mass as a Measure of Dynamic Postural Control Following Concussion
}

\author{
Sarah Patejak ${ }^{1}$ Joshua Forrest ${ }^{2}$, Emily Harting ${ }^{3}$, Mable Sisk ${ }^{4}$ Eric Schussler $^{2}$ (D) ${ }^{a}$ \\ 1 The James A. Haley Veteran's Hospital, ${ }^{2}$ School of Rehabilitation Sciences, Physical Therapy, Old Dominion University, ${ }^{3}$ Wardell Orthopedics, ${ }^{4}$ \\ Sentara Healthcare, Great Bridge Sports and Orthopedic Therapy Center \\ Keywords: movement system, gait, dynamic stability, concussion, center of mass
}

https://doi.org/10.26603/001c.27983

\section{International Journal of Sports Physical Therapy}

Vol. 16, Issue 5, 2021

\section{Background}

The incidence of sports-related concussion in the US is between 1.6-3.8 million annually. Identification of ongoing impairment post-concussion continues to be challenging, as research indicates many patients are cleared for return to activity while still suffering subclinical impairment of function. Purpose: To identify and review the current literature on the use of center of mass (COM) during gait as a potential indicator variable after concussive injury. Study Design: Systematic Review

\section{Methods}

A Pubmed search was undertaken utilizing search terms involving gait performance and concussion. Study inclusion criteria included: (1) COM used as a variable in data analysis, (2) study population included individuals diagnosed with concussion, (3) postural control was evaluated throughout the recovery process. Articles were excluded if they were systematic reviews, unedited manuscripts, meta-analyses, or were more than 15 years old.

\section{Results}

Search of the PubMed database identified six articles which matched the determined criteria. The average STROBE score was 26.5/34 (range from 23-30). The areas that had the poorest scoring were bias, study size, statistical methods, participants, descriptive data, and main results. Results of the review indicate that COM displacement was higher in concussion groups with a sufficiently taxing task, such as a dual task paradigm.

\section{Conclusion}

Center of mass measures during gait may be an indicator of ongoing concussive injury involvement after clinical indications have subsided.

\section{Level of Evidence}

$2 \mathrm{a}$

\section{INTRODUCTION}

The incidence of sports-related concussion, also known as mild traumatic brain injury (mTBI), in the US is between 1.6-3.8 million annually. ${ }^{1}$ "Sport related concussion is a traumatic brain injury induced by biomechanical forces" 2 and is an area of interest in research for diagnosis, deficits, intervention, and recovery. Typically, relative rest is rec- ommended until symptoms have resolved, which typically takes around seven days and occurs in about $90 \%$ of individuals. ${ }^{3}$ Symptoms and presentation vary extensively between patients, and can include impairments in cognitive function, motor tasks such as balance and coordination, visual acuity, and reaction time, among many others.

Originally, concussion diagnosis was based on a graded scale based on symptom severity at initial presentation. ${ }^{4}$

\footnotetext{
a Corresponding author:

Eric Schussler

Old Dominion University, School of Rehabilitation Sciences, Physical Therapy -

4608 Hampton Blvd, Norfolk, VA 23529

eschussl@odu.edu
} 
Currently, there is no definitive objective diagnostic test or biomarker clinicians can rely on for an immediate diagnosis. Because a concussion injury is highly variable, both in symptoms and duration, classification is difficult. Time to full recovery is the current standard for measuring injury severity. ${ }^{5}$ At this time, a battery of subjective and objective measures are used both at initial presentation and at subsequent re-examinations, all evaluating different aspects of impaired function. ${ }^{4}$ However, the specific variables each of these tools utilize to make their determinations of an individual's level of function may not be appropriate for the tasks they are intended to evaluate. This could potentially lead to return to participation in activities that carry a risk of reinjury prior to full functional recovery.

Any collection of concussion symptoms that persists for longer than two weeks and impacts an individual's daily function is considered diagnostic criteria for Post-Concussion Syndrome (PCS). ${ }^{6}$ There is currently no way to definitively predict the development of PCS, as biomechanics of the impact and the severity of the impact have not been shown to be related to the onset of PCS. ${ }^{7}$ Risk factors for PCS include retrograde amnesia, difficult concentrating, disorientation, insomnia, loss of balance, sensitivity to noise and visual disturbances after injury. ${ }^{8}$ There are a variety of accepted diagnostic outcome measures that are used for identifying concussion and PCS that have evolved as new research has elucidated the complexities of the conditions. ${ }^{6}$

Center of mass (COM) as a measure to determine dynamic postural stability has been examined for efficacy as a diagnostic tool and as an outcome measure for use in concussion rehabilitation. Statically, COM is the point where the mass of the body is centered and is usually located just below the umbilicus in quiet standing. ${ }^{9}$ During gait, COM shifts in a predictable pattern toward the foot that is stepping and also at a predictable velocity determined by the gait speed of the individual. ${ }^{3}$ Previous studies have examined whole-body COM motion during ambulation with kinematic measurements to examine recovery of gait balance control after sustaining a concussion. ${ }^{10}$ Previous research has also identified significant changes in COM sway and velocity during gait with the addition of a dual-task paradigm via a cognitive component up to 28 days post-injury with little attention paid to the remainder of recovery time. ${ }^{11}$

Due to the diverse presentation of concussion and PCS, there is no evident consensus for clearance of an individual to return to their prior level of function and activity. ${ }^{6}$ It is imperative to avoid clearing an individual too soon, especially in the athletic population, to decrease the risk of sustaining a second head injury. ${ }^{3,6}$ In addition, returning prior to full recovery has been indicated to slow the general rate of symptom resolution and prolong the presence of problematic deficits. ${ }^{3,6}$ In order to more definitively determine when discharge from monitored care is appropriate and safe, objective measures must be evaluated for their ability to detect meaningful differences. The purpose of this systematic review is to identify and review the current literature on the use of center of mass (COM) during gait as a potential indicator variable after concussive injury.

\section{METHODS}

\section{EVIDENCE ACQUISITION}

The PubMed database was searched for relevant, peer-reviewed articles published in English from the inception of the database until November 19, 2019. The search strategy included two concepts (gait, and concussion) and a combination of associated key words and $\mathrm{MeSH}$ terms tailored to the database (APPENDIX 1). All located articles were handsearched by two study authors (EH and SP) to confirm the presence of assessment related to balance, posture, or postural control in combination with gait and concussion. Reference lists of all relevant articles were hand-searched for additional relevant articles by four study authors (JF, EH, SP, \& MS)

Four study authors (JF, EH, SP, \& MS) independently screened all articles for study inclusion criteria: (1) COM used as a variable in data analysis, (2) study population included individuals diagnosed with concussion, (3) postural control was evaluated throughout the recovery process. Articles were excluded if they were systematic reviews, unedited manuscripts, meta-analyses, or were more than 15 years old. Articles that studied postural control but did not use COM as a measurable variable were also excluded. Author consensus for inclusion was achieved through discussion.

Four authors (JF, EH, SP, \& MS) independently reviewed the methods and standards of quality of six articles using the STROBE quality assessment tool, 12 and the Downs and Black bias assessment. ${ }^{13}$ The STROBE tool is validated for content and initial construct validity and inter-rater reliability for cohort studies through asking 34 questions of selection bias, study design, confounders, blinding, data collection methods, withdrawals and dropouts, intervention integrity, and analysis. The max rating is a 34 with higher scores indicating higher quality. ${ }^{12}$ The Downs and Black scale is validated for use in assessing the bias of cohort studies by asking 27 focused questions, with scoring of 0 for no, or 1 for yes. ${ }^{13}$ Higher scores indicate a lower risk of bias.

Four authors (JF, EH, SP, \& MS) performed data extraction: study design, purpose, healthy/control subjects (\#, demographics), injured/case subjects (\#, demographics), inclusion and exclusion criteria, setting, dependent variables, independent variables, intervention, procedures, equipment/ collection parameters, statistical analysis performed, summary of results, threats to internal validity, threats to external validity, and conclusions. All data used in the review was captured using these parameters. Four authors (JF, $\mathrm{EH}, \mathrm{SP}$, \& MS) completed an assessment of the level of evidence and strength of recommendation (SORT) for each accepted study.

\section{RESULTS}

Search of the PubMed database yielded 259 articles. After screening for duplicates this number dropped to 107 records. Title and abstract screening yielded 22 articles for full-text review. Author agreement for inclusion/exclusion prior to full-text review and after full-text review was satisfactory. Ultimately, six articles $3,4,6,11,14,15$ met the inclu- 


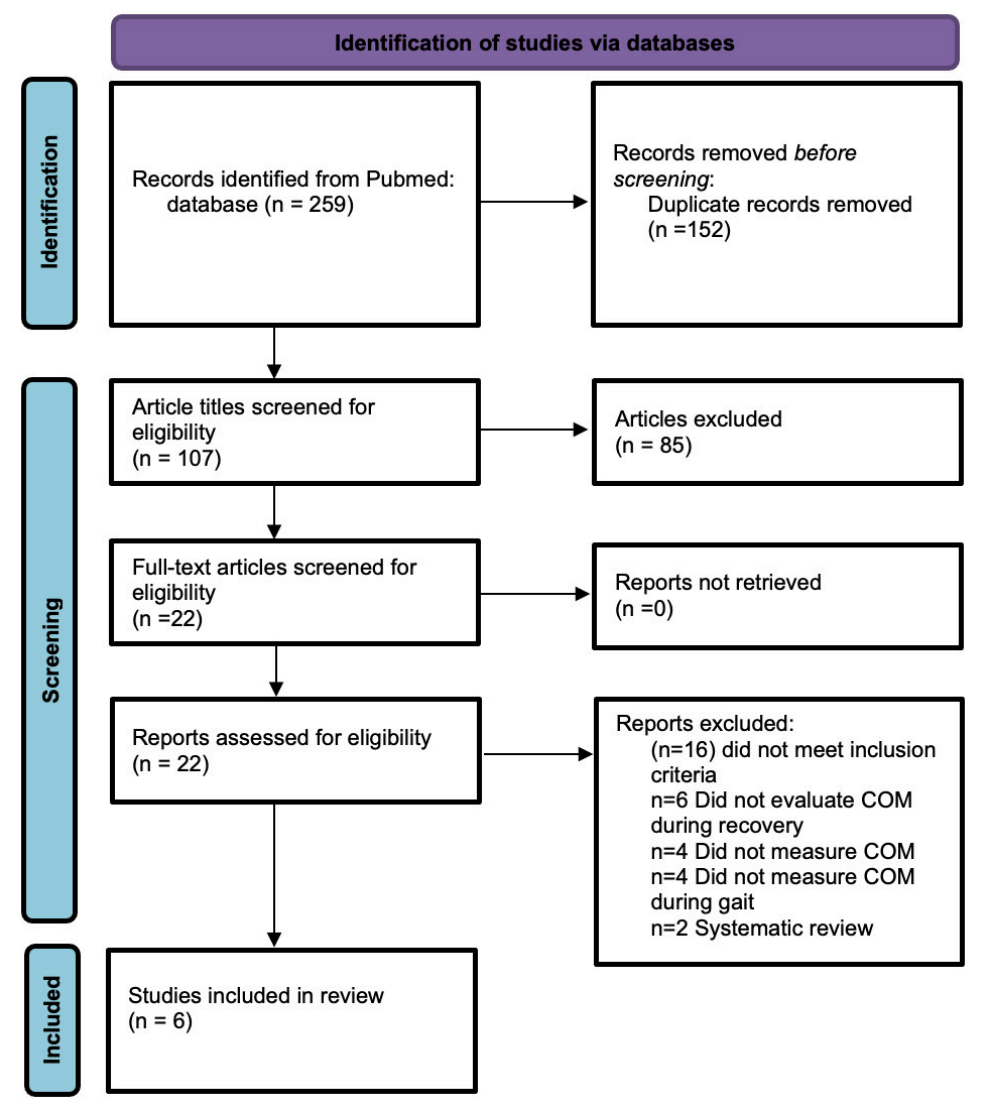

Figure 1. PRISMA flow chart.

sion criteria and quality and bias standard and were accepted for inclusion into this systematic review. Analysis was completed on the final six articles (Figure 1). All studies included are cohort studies with a SORT, level $2^{16}$ and level 4 evidence as noted with the Downs and Black bias assessment. 13

Of the six included articles, the average quality ${ }^{12}$ score was 26.5/34 (range from 23-30). The areas that had the poorest scoring were bias, study size, statistical methods, participants, descriptive data, and main results. There was one similar author group, but it was found that they had similar assessment windows and outcome measures with use of different population groups. 6,15

All six of the articles (100\%) were cohort studies, $13,4,6,6,11$ two articles (33.3\%) performed prospective testing occurring five separate times, $, 6,15$ and four articles (66.6\%) were longitudinal with testing times ranging between five to seven separate sessions. ${ }^{6,11,14,15}$ All articles assessed COM during gait. Participants ranged in age from 14 to 27 years, and most were high school or collegiate athletes. 3,4,6,11,14,15 None of the studies reported results based on sex, and four had no further delineations beyond concussion diagnosis compared to controls. ${ }^{3,4,6,14}$ One study compared adolescent and young adult age groups. ${ }^{15}$ One article delineated concussed and non-concussed athletes, and fur- ther divided these groups into high- and low-velocity impact groups. ${ }^{11}$ One study delineated groups of high school athletes and their recovery before return to activity (RTA) and after RTA. ${ }^{6}$ A diagnosis of concussion was made using the American Academy of Neurology's definition for two studies, 3,11 the McCrory et al ${ }^{15}$ definition for three studies, ${ }^{4,6,15}$ and was not specified in one study. ${ }^{14}$ Diagnoses were made exclusively by physicians in two studies, ${ }^{4,14}$ and by either a physician or a certified athletic trainer in the other four. ${ }^{3,6,11,15}$ Details of study design and quality reporting scores are summarized in Table 1.

Participants were initially assessed within 48 to 72 hours in four of the studies, $3,6,11,15$ while two of the studies did not state when initial assessment occurred. ${ }^{4,14}$ Reassessment did not occur in one study. ${ }^{4}$ Two studies followed participants for one month with weekly testing dates. 3,11 Two studies followed participants for two months with followup sessions at one week, two weeks, one month, and two months. ${ }^{6,15}$ One study followed participants with weekly testing for six weeks and a one-year post-injury follow up. ${ }^{14}$ Four studies did not specify if practice trials were allowed, $6,11,14,15$ while two allowed unlimited practice before data points were collected. 3,4 The experimental protocol, assessment time points, and study results are summarized in Table 2. 
Table 1. Study Design and Participant Characteristics of Articles Included in the Systematic Review

\begin{tabular}{|c|c|c|c|c|c|c|}
\hline Study & $\begin{array}{l}\text { Study } \\
\text { Design }\end{array}$ & Inclusion Criteria & Exclusion Criteria & $\begin{array}{l}\text { Concussed } \\
\text { Participants }\end{array}$ & $\begin{array}{l}\text { Non- } \\
\text { concussed } \\
\text { Participants }\end{array}$ & $\begin{array}{l}\text { STROBE } 10 \\
(0-34) / \\
\text { Downs \& } \\
\text { Black } \\
\text { (0-27) } \\
\text { Scores }\end{array}$ \\
\hline $\begin{array}{l}\text { Fino, et } \\
\text { al }^{6} \\
(2016)\end{array}$ & $\begin{array}{l}\text { Longitudinal } \\
\text { exam of the } \\
\text { local } \\
\text { dynamic } \\
\text { Stability } \\
\text { (LDS) of } \\
\text { recently } \\
\text { concussed } \\
\text { and } \\
\text { matched } \\
\text { control } \\
\text { athletes }\end{array}$ & $\begin{array}{l}\text { mTBI group: diagnosis of mTBI based on } \\
\text { VHA/DoD criteria with persisting symptoms } \\
\text { >3 after injury; Between } 21-50 \text { years old; } \\
\text { minimal cognitive impairment; score of } \\
\text { between 0-8 on Short Blessed test for } \\
\text { cognitive function; may/may not had loss of } \\
\text { consciousness after initial injury Control } \\
\text { group: between } 21-50 \text { years old; no hx of } \\
\text { mTBI/brain injury }\end{array}$ & $\begin{array}{l}\text { Have had/currently have any other injury, medical, } \\
\text { substance or neurological illness that could potentially } \\
\text { Explain balance deficits (i.e. - CNS disease, stroke, moderate } \\
\text { TBI, lower extremity amputation); meet criteria for } \\
\text { moderate to severe substance use disorder within the past } \\
\text { month (DSM-V); display behavior that would significantly } \\
\text { interfere with validity of data collection or safety during } \\
\text { study; be in significant pain during eval ( } 5 / 10 \text { subjectively); } \\
\text { pregnant female; history of peripheral vestibular pathology } \\
\text { or ocular motor deficits; significant hearing loss unable to } \\
\text { abstain from use of medications for } 24 \text { hours prior to testing } \\
\text { (meds might impair balance) }\end{array}$ & $\begin{array}{l}5 \text { concussed } \\
\text { Varsity } \\
\text { athletes }\end{array}$ & $\begin{array}{l}4 \text { matched } \\
\text { varsity } \\
\text { athletes; } \\
\text { recruited } \\
\text { from } \\
\text { teammates } \\
\text { of concussed } \\
\text { subjects - } \\
\text { matched by } \\
\text { sport } \\
\text { position, skill } \\
\text { level, and } \\
\text { height }\end{array}$ & $30 / 17$ \\
\hline $\begin{array}{l}\text { Parker, } \\
\text { et al }{ }^{10} \\
(2008)\end{array}$ & $\begin{array}{l}\text { Longitudinal } \\
\text { cohort } \\
\text { study }\end{array}$ & $\begin{array}{l}\text { All concussed subjects had sustained a Grade } \\
2 \text { concussion according to the American } \\
\text { Academy of Neurology Practice Parameter. } \\
\text { Concussed participants were initially } \\
\text { identified by medical personnel including } \\
\text { certified athletic trainers and attending } \\
\text { medical doctors in the university } \\
\text { intercollegiate athletic program and the } \\
\text { student health center and were referred for } \\
\text { testing as soon as possible following the } \\
\text { injury. None of the NORM subjects self- } \\
\text { reported a history of neurological diseases, } \\
\text { visual impairment not correctable with } \\
\text { lenses, musculoskeletal impairments, or } \\
\text { persistent symptoms of vertigo, } \\
\text { lightheadedness, unsteadiness, falling or a } \\
\text { history of concussion within the last year. }\end{array}$ & Not reported & $\begin{array}{l}28 \text { Grade } 2 \\
\text { concussed } \\
\text { individuals } \\
\text { (14 athletes } \\
\text { and } 14 \text { non- } \\
\text { athletes) }\end{array}$ & $\begin{array}{l}28 \text { uninjured } \\
\text { matched } \\
\text { controls (14 } \\
\text { athletes and } \\
14 \text { non- } \\
\text { athletes); } \\
\text { The control } \\
\text { subjects } \\
\text { were } \\
\text { matched to } \\
\text { concussed } \\
\text { subjects by } \\
\text { gender, age, } \\
\text { height, } \\
\text { weight, and } \\
\text { physical } \\
\text { activity }\end{array}$ & $27 / 14$ \\
\hline $\begin{array}{l}\text { Catena, } \\
\text { et al }{ }^{2} \\
(2009)\end{array}$ & $\begin{array}{l}\text { Longitudinal } \\
\text { cohort } \\
\text { study }\end{array}$ & $\begin{array}{l}\text { Student health center/athletic team } \\
\text { physicians/trainers of university campus } \\
\text { examined participants for mTBIs including } \\
\text { those diagnosed with grade II concussions } \\
\text { defined by American Academy of Neurology } \\
\text { Practice Parameters }\end{array}$ & $\begin{array}{l}\text { Concussion symptoms lasting longer than } 15 \text { minutes but no } \\
\text { loss of consciousness, pre-existing abnormalities of gait, or } \\
\text { cognition, no prior concussions in the previous year. }\end{array}$ & $\begin{array}{l}30 \\
\text { university } \\
\text { subjects } \\
\text { with grade } 2 \\
\text { mTBI. }\end{array}$ & $\begin{array}{l}30 \text { control } \\
\text { subjects } \\
\text { matched by } \\
\text { gender, age, } \\
\text { mass, height, } \\
\text { level of }\end{array}$ & $23 / 16$ \\
\hline
\end{tabular}




\begin{tabular}{|c|c|c|c|c|c|c|}
\hline Study & $\begin{array}{l}\text { Study } \\
\text { Design }\end{array}$ & Inclusion Criteria & Exclusion Criteria & $\begin{array}{l}\text { Concussed } \\
\text { Participants }\end{array}$ & $\begin{array}{l}\text { Non- } \\
\text { concussed } \\
\text { Participants }\end{array}$ & $\begin{array}{l}\text { STROBE }^{10} \\
(0-34) / \\
\text { Downs \& } \\
\text { Black } \\
\text { (0-27) } \\
\text { Scores }\end{array}$ \\
\hline & & & & & $\begin{array}{l}\text { education } \\
\text { and athletic } \\
\text { participation. }\end{array}$ & \\
\hline $\begin{array}{l}\text { Howell, } \\
\text { et al } \\
\text { (2015) }\end{array}$ & $\begin{array}{l}\text { Prospective } \\
\text { longitudinal } \\
\text { cohort } \\
\text { study }\end{array}$ & $\begin{array}{l}\text { Individuals sustaining a concussion were } \\
\text { diagnosed and identified for potential } \\
\text { inclusion in the study by a physician or } \\
\text { athletic trainer as described by: direct blow } \\
\text { to head, face, neck, or elsewhere with force } \\
\text { transmitted to head resulting in impaired } \\
\text { neurological function. }\end{array}$ & $\begin{array}{l}\text { Lower extremity deficiency/injury that may affect normal } \\
\text { gait, history of cognitive deficiencies (memory loss, } \\
\text { decreased concentration), history of } 3+\text { previous } \\
\text { concussions, loss of consciousness from the concussion }>1 \\
\text { min., history of ADHD, previously documented concussion in } \\
\text { the past year. }\end{array}$ & $\begin{array}{l}19 \text { local high } \\
\text { school } \\
\text { students. }\end{array}$ & $\begin{array}{l}19 \text { control } \\
\text { subjects } \\
\text { matched by } \\
\text { sex, height, } \\
\text { mass, age, } \\
\text { and sport. }\end{array}$ & $28 / 17$ \\
\hline $\begin{array}{l}\text { Doherty, } \\
{\text { et } \mathrm{al}^{3}} \\
\text { (2017) }\end{array}$ & $\begin{array}{l}\text { Cohort } \\
\text { study }\end{array}$ & $\begin{array}{l}\text { Convenience recruiting of patients at a clinic } \\
\text { in Ireland who had sustained a concussion } \\
\text { within } 1 \text { month, dx by physician consistent } \\
\text { with latest international consensus on } \\
\text { definition }\end{array}$ & $\begin{array}{l}\text { Any lower extremity injury that may affect gait, hx of } \\
\text { cognitive deficiencies, hx of } 3+\text { previous concussions } \\
\text { (chronic mTBI), loss of consciousness following concussion } \\
>1 \text { min, previously documented concussion in the previous } \\
\text { year }\end{array}$ & $\begin{array}{l}15 \\
\text { concussion } \\
\text { patients (4 } \\
\text { females, } 11 \\
\text { males) }\end{array}$ & $\begin{array}{l}15 \text { age and } \\
\text { sex-matched } \\
\text { controls }\end{array}$ & $25 / 12$ \\
\hline $\begin{array}{l}\text { Howell, } \\
\text { et al } \\
(2015)\end{array}$ & $\begin{array}{l}\text { Cohort } \\
\text { Study }\end{array}$ & $\begin{array}{l}\text { High school and college students who } \\
\text { sustained a concussion were diagnosed and } \\
\text { identified for potential inclusion in the study } \\
\text { by a certified athletic trainer or physician. } \\
\text { The definition of concussion was consistent } \\
\text { with that described by McCrory et al } 2^{2} \text { : an } \\
\text { injury caused by a direct blow to the head, } \\
\text { face, neck, or elsewhere on the body with an } \\
\text { impulsive force transmitted to the head, } \\
\text { resulting in a graded set of clinical symptoms. }\end{array}$ & $\begin{array}{l}\text { Exclusion criteria for all prospective subjects included the } \\
\text { following: (1) lower extremity deficiency or injury that may } \\
\text { affect normal gait patterns; (2) history of cognitive } \\
\text { deficiencies, such as permanent memory loss or } \\
\text { concentration abnormalities; ( } 3 \text { ) history of } 3 \text { or more } \\
\text { previous concussions; (4) loss of consciousness from the } \\
\text { concussion lasting longer than } 1 \text { minute; (5) history of } \\
\text { attention-deficit hyperactivity disorder; or (6) a previously } \\
\text { documented concussion within the past year. Consistent } \\
\text { with previous work, potential subjects with } 3 \text { or more } \\
\text { previous concussions were not included in the study to } \\
\text { ensure, to the extent possible, that those with chronic mild } \\
\text { traumatic brain injury were not a part of the study. } \\
\text { Additionally, those who experienced a loss of consciousness } \\
\text { for greater than } 1 \text { minute were excluded because of the role } \\
\text { that this sign plays in concussion management modification }\end{array}$ & $\begin{array}{l}\text { A total of } 38 \\
\text { subjects } \\
\text { with } \\
\text { concussion, } \\
19 \text { young } \\
\text { adults } \\
\text { (mean 6 SD } \\
\text { age, } 20.36 \\
2.4 \text { years) } \\
\text { and } 19 \\
\text { adolescents } \\
\text { (mean 6 SD } \\
\text { age, } 15.16 \\
1.1 \text { years) } \\
\text { [19 young } \\
\text { adults } \\
\text { (mean }+/- \\
\text { SD age, } 20.3 \\
+/-2.4 \\
\text { years) and } \\
19\end{array}$ & $\begin{array}{l}38 \\
\text { individually } \\
\text { matched } \\
\text { control } \\
\text { subjects: } \\
\text { Matched for } \\
\text { sex, age, } \\
\text { height, mass, } \\
\text { activity } \\
\text { participation }\end{array}$ & $26 / 12$ \\
\hline
\end{tabular}


A Systematic Review of Center of Mass as a Measure of Dynamic Postural Control Following Concussion

\begin{tabular}{|c|c|c|c|c|c|c|}
\hline Study & $\begin{array}{l}\text { Study } \\
\text { Design }\end{array}$ & Inclusion Criteria & Exclusion Criteria & $\begin{array}{l}\text { Concussed } \\
\text { Participants }\end{array}$ & $\begin{array}{l}\text { Non- } \\
\text { concussed } \\
\text { Participants }\end{array}$ & $\begin{array}{l}\text { STROBE } 10 \\
(0-34) / \\
\text { Downs \& } \\
\text { Black } \\
(0-27) \\
\text { Scores }\end{array}$ \\
\hline & & & & $\begin{array}{l}\text { adolescents } \\
\text { (mean }+/- \\
\text { SD age, } 15.1 \\
+/-1.1 \\
\text { years)] }\end{array}$ & & \\
\hline
\end{tabular}

Abbreviations: mTBI: mild traumatic brain injury, VHA/DoD: Veterans Health Affairs/ Department of Defense, CNS: central nervous system, TBI: Traumatic brain injury 
Table 2. Center of Mass (COM) Assessment Protocol and Results

\begin{tabular}{|c|c|c|c|}
\hline Study & Gait COM Protocol & $\begin{array}{l}\text { Assessment } \\
\text { Time Points }\end{array}$ & Study Results \\
\hline $\begin{array}{l}\text { Fino, et } \\
\text { al6 } \\
(2016)\end{array}$ & $\begin{array}{l}2 \text { six-axis IMUs aligned in the mediolateral, } \\
\text { vertical, and anterior posterior directions with } \\
\text { data sampled at } 128 \mathrm{~Hz} \text { during single task and } \\
\text { dual task gait. } 18 \mathrm{~m} \text { walkway }\end{array}$ & $\begin{array}{l}\text { Assessed } \\
\text { weekly for } \\
\text { six weeks } \\
\text { and a one- } \\
\text { year follow- } \\
\text { up } \\
\text { assessment. }\end{array}$ & $\begin{array}{l}\text { Single Task: no differences in stability or variability between groups; no significant main effects of group, week or } \\
\text { task found for stride time, variability, } \lambda \text { s-Trunk, or } \lambda \text { s-Head. Dual Task: gait speed was slower than single task gait } \\
\text { speed, with increased speed over time. }\end{array}$ \\
\hline $\begin{array}{l}\text { Parker, } \\
\text { et al }{ }^{10} \\
(2008)\end{array}$ & $\begin{array}{l}\text { External markers and estimated joint centers } \\
\text { were used to calculate } 3 \text {-dimensional motion for } \\
\text { individual body segments and locations of } \\
\text { segmental COM. Two COM variables were } \\
\text { examined: (1) the COM displacement in the } \\
\text { medial-lateral direction and (2) the maximum } \\
\text { separation between COM and COP of the } \\
\text { supporting foot in the anterior direction. The } \\
\text { relationship between the whole-body COM and } \\
\text { the base of support (shown to be a sensitive } \\
\text { measure of gait imbalance), } 10 \mathrm{~m} \text { walkway }\end{array}$ & $\begin{array}{l}\text { Assessed } \\
48 \text { hours } \\
\text { after injury } \\
\text { concussed), } \\
\text { day } 2 \text { (non- } \\
\text { concussed), } \\
\text { day } 5 \text { (all), } \\
\text { day } 14 \text { (all), } \\
\text { and day } 28 \\
\text { (all) }\end{array}$ & $\begin{array}{l}\text { Gait imbalance during the divided attention condition was marked by greater sway and sway velocity of the whole- } \\
\text { body COM that was maintained for up to } 28 \text { days following injury. }\end{array}$ \\
\hline $\begin{array}{l}\text { Catena, } \\
\text { et al }{ }^{2} \\
(2009)\end{array}$ & $\begin{array}{l}29 \text { retroreflective markers attached to } \\
\text { anatomical landmarks while } 3 \mathrm{D} \text { marker } \\
\text { trajectories were taken with eight camera motion } \\
\text { tracking system at } 60 \mathrm{~Hz} \text {, then filtered with low- } \\
\text { pass fourth order Butterworth filter at cutoff } \\
\text { frequency of } 8 \mathrm{~Hz} \text {. Marker position data was used } \\
\text { to locate segmental COM of a thirteen-link } \\
\text { model: head, trunk, two upper arms, two lower } \\
\text { legs, pelvis, two thighs, two shanks, two feet. }\end{array}$ & $\begin{array}{l}\text { Assessed } \\
48 \text { hours, } \\
\text { on the 6th } \\
\text { day, 14th } \\
\text { day, and } \\
28 \text { th day } \\
\text { post-injury. }\end{array}$ & $\begin{array}{l}\text { Concussed individuals significantly reduced peak anteroposterior velocity during dual task walking on day } 2 \text {. Peak } \\
\text { mediolateral velocity was significantly reduced by day } 14 \text { during short obstacle crossing. }\end{array}$ \\
\hline $\begin{array}{l}\text { Howell, } \\
\text { et al } \\
\text { (2015) }\end{array}$ & $\begin{array}{l}29 \text { retroreflective markers placed on bony } \\
\text { landmarks of the patient with whole body motion } \\
\text { analysis performed using a } 10 \text {-camera motion } \\
\text { analysis system at a sampling rate of } 60 \mathrm{~Hz} \\
\text { capturing and reconstructing 3D trajectory of } \\
\text { each marker. Marker trajectory data was low-pass } \\
\text { filtered using the fourth-order Butterworth filter } \\
\text { with cutoff frequency set to } 8 \mathrm{~Hz} \text {. whole body } \\
\text { COM positions were calculated as the weighted } \\
\text { sum of all } 13 \text { body segments to represent the } \\
\text { whole body. } 15 \mathrm{~m} \text { walkway }\end{array}$ & $\begin{array}{l}\text { Assessed } \\
\text { within } 72 \\
\text { hours of } \\
\text { injury and } 1 \\
\text { week, } 2 \\
\text { weeks, } 1 \\
\text { month, and } \\
2 \text { months } \\
\text { post-injury. }\end{array}$ & $\begin{array}{l}\text { Concussion group: Significant differences were found in group-time interaction between dual-task walking for } \\
\text { mediolateral displacement of COM and COM medial-lateral velocity. Significant worsening of COM control after } \\
\text { return to activity was also illustrated during dual-task walking. Overall mean return to activity mediolateral } \\
\text { displacement was significantly greater than controls for same time point measurements when dual-tasking gait. } \\
\text { The percent change value of medial-lateral velocity during dual-task walking was significantly greater. Peak COM } \\
\text { anterior velocity was also decreased in percent change value between pre- and post-return to activity while dual- } \\
\text { tasking gait There was a significant group-time interaction pre- and post-return to activity in clinical symptom } \\
\text { scores. Pre-Return timepoints between tests } 2 \text { and } 1 \text { changed significantly more than that of controls which } \\
\text { showed little to no change for either testing interval. Additionally, mean pre- and post-return to activity changes } \\
\text { were significantly different than controls for clinical symptoms. }\end{array}$ \\
\hline
\end{tabular}

Abbreviations: IMU: inertial measurement unit, COP: Center of Pressure, $\lambda$ s: Lyapunov exponents 


\section{POSTURAL CONTROL PARADIGMS}

\section{STUDY OUTCOME VARIABLES}

All studies used flat surfaces for experimental walkways that ranged from 10 to $18 \mathrm{~m}$ in length in four studies, $4,6,11,14$ though the length was not specified in the other two protocols. ${ }^{3,6}$ All six studies utilized self-selected walking speeds for dynamic tasks, and all subjects were tested in the barefoot condition. 3,4,6,11,14,15 Two studies used accelerometers to capture motion data, ${ }^{4,14}$ another two used force plates embedded within the experimental walkways, ${ }^{3,4}$ and four studies utilized reflective markers and multiple camera motion analysis to collect changes in COM excursion, velocity, and acceleration. 3,6,11,15 Only one study used obstacles negotiation as a separate condition. ${ }^{3}$

Five of the six studies (83.3\%) added a cognitive component to assess dual-tasking ability of subjects during gait. $3,6,11,14,15$ In two studies, participants were given a random number and asked to serially subtract by 7's, ${ }^{11,14}$ one of the studies utilized backwards spelling and recitation of the months of the year in reverse, ${ }^{11}$ and another utilized question-and-answer verbal response. ${ }^{3}$ Two studies performed the Stroop cognitive assessment during walking trials, where subjects are asked to compare whether an auditory and a visual cue given simultaneously are the same or different. ${ }^{6,15}$ Instructions were given verbally for all studies.

\section{SINGLE-TASK DYNAMIC VARIABLES}

All six studies examined dynamic variables related to COM, specifically excursion of the COM during gait and peak velocity. These were evaluated along two straight anatomical planes: the anterior-posterior (AP) and medio-lateral (ML). In six articles, these were assessed using computer analysis of the data gathered from various technology (force plates, 3,4 accelerometers, 4,14 and/or motion capture systems $\left.\mathrm{s}^{3,6,11,15}\right)$. Five studies described COM excursion in whole-body terms, $3,4,6,11,15$ while one study split the COM into head and trunk segments. ${ }^{14}$ Three studies showed greater ML sway, or COM excursion, in concussed individuals versus controls during single-task walking. 3,6,15 This difference was also reflected in the one study that included an obstacle negotiation condition. ${ }^{3}$ One study split the groups into athletes and non-athletes, and found that ML sway was significantly greater for athletes, regardless of presence of concussion. ${ }^{11}$ Peak COM velocities were slower in concussed groups versus controls in the ML plane in three studies $^{6,15}$ and in the AP plane in three studies. ${ }^{3,4,11}$ No significant differences were found between concussion subgroups or control groups for any single-task dynamic variables across all studies.

\section{DUAL-TASK DYNAMIC VARIABLES}

A cognitive component was added to dynamic tasks in five of the six studies reviewed, 3,4,6,11,15 as described previously. Only two of the studies reported accuracy on the specific cognitive task, ${ }^{6,15}$ while the others simply used a cognitive task to create a dual-task condition.3,4,11,14 One of the studies showed decreased performance on the cognitive task in the adolescent versus young adult groups throughout all testing days, ${ }^{15}$ while another saw no significant differences between groups in cognitive task performance. ${ }^{6}$ During dual-task trials, three studies showed significantly slowed gait speed as measured by total COM displacement over time. ${ }^{6,14,15}$

Four of the six studies compared single- and dual-task conditions. ${ }^{3,6,11,14}$ ML sway of the COM also increased significantly from the single-task condition in two of the studies across both concussed and non-concussed groups. ${ }^{3,11}$ In the study that compared athletes to nonathletes, athletes still displayed greater ML COM sway during the dual-task condition, regardless of concussion status, though the concussed athlete group displayed the greatest ML sway over all other testing conditions. ${ }^{11}$ ML COM velocity was significantly decreased between single- and dual-task conditions in two studies, ${ }^{3,11}$ and increased in one study. ${ }^{6}$ Two studies showed significantly decreased peak COM AP velocity during dual-task walking. ${ }^{6,11}$

\section{NEUROPSYCHOLOGICAL TESTS AND POST-CONCUSSION SYMPTOM SCALES}

In total, three of six articles $4,6,15$ referenced use of neuropsychological tests or post-concussion symptom scales and a secondary outcome measure of interest. There were two articles that note neuropsychological test and postconcussion symptom scales as a part of their data collection. Howell et $\mathrm{al}^{6}$ used cognitive assessment via Attentional Network Test (ANT) and a Task Switching Test (TST) for initial assessment, yielding a significant interaction preand post-return to activity in the clinical symptom scores. Participants in the concussed group showed significant differences in pre- and post-return to activity scores. ${ }^{6}$ Two articles 4,15 cited use of the SCAT3 symptom checklist and reported that adolescents had greater symptom severity compared to the control group. ${ }^{15}$ Doherty et al. ${ }^{4}$ had reports of poorer perceived health in the concussed group compared to the control group with use of the SCAT3 symptom scale. The remaining three articles ${ }^{3,11,14}$ did not assess or report neuropsychological and post-concussion symptom scales as a part of their studies.

\section{DISCUSSION}

Based on this review, COM appears to be an accurate measure of dynamic postural control in the post-concussion population ( $\leqslant 1$ year) under both single- and dual-task conditions. Despite the accuracy and usefulness of the measure in the laboratory setting, the clinical utility of COM is limited due to the substantial technology required to detect subtle post-concussive motor control deficits. Knowledge of COM as a valuable stand-alone measure does have a practical clinical function; however, when compared to the precision of technology-driven assessments, the subjective nature of current balance outcome measures remains a weakness in concussion management. This is of particular importance when considering that the subtle motor impairments that occur post-concussion appear to persist even when symptoms have seemingly resolved. ${ }^{17}$ 
There is no gold standard outcome measure to clinically assess dynamic balance and postural control, nor have normative values been established for ML or AP sway in the post-concussion population. In addition, there is no standard battery of outcome measures in use in the research setting. At present, strong recommendations for the use of post-concussion balance/postural control outcome exams remain in question. A recent clinical practice guideline expressly made no recommendations of functional outcome measures and states "there is insufficient evidence to support a clear set of motor function measures for individuals who have experienced a concussive event."17 The TBI Evidence Database to Guide Effectiveness (EDGE), has recommended three functional balance measures for clinical use in the TBI population: the Balance Error Scoring System (BESS), the Berg Balance Scale (BBS), and the Community Balance and Mobility Scale (CBMS). ${ }^{18}$ All have been validated in the concussion population and are considered clinically useful in the outpatient setting; however, their use in research to establish normative values of postural control variables such as COM is largely absent.

In addition to balance, gait velocity may be considered a useful measure in post-concussion recovery assessment. Gait velocity can be measured simply with markings on the floor and a stopwatch, and there are well-known values for safe ambulation speed; ${ }^{19}$ however, the reviewed studies did not offer any normative values for gait speed in post-concussion subjects when compared to the COM variables. Despite the clinical utility of gait velocity, this measure is often imprecise and unable to capture the subtle deficits that often remain after more obvious post-concussion symptoms have resolved. Current research is advancing the study of COM velocity to determine standardized values for singletask gait, single- vs. dual-task static and dynamic conditions, and sport-specific criteria (running, cutting) for clinical application. ${ }^{3,6,11}$ In addition to research, technology such as force plates, pressure-sensitive walkways, and motion capture offer a more precise method of COM variable calculation and assessment than visual estimation of sway or deviation counting such as in the BESS test. $3,4,11,14,15$ For COM assessment to become clinically useful, normative values will need to be established for the measure in all planes of motion, and technology will need to be readily available in patient care settings to help establish appropriate and meaningful concussion treatment protocols. Gait velocity as a measure of concussion recovery may be a useful measure due to the applicability to both return-to-sport activities and ability to complete activities of daily living (ADLs)

More research for standardized COM values in this population would be beneficial to determine what significant differences in COM sway/displacement in different planes and how those differences relate to function. Measurement of ML (increased post-concussion) ${ }^{11}$ and AP (decreased postconcussion) ${ }^{11}$ displacement of the COM is not clinically feasible unless clinicians have easy access to technology, are already trained in how to capture and analyze data, and are able to interpret the results. Lower-tech versions of clinical measures related to the sway of the COM that are currently used in clinical practice generally relate to static postural control tasks and do not incorporate dynamic conditions as might be encountered on the playing field or in daily living. These include assessments such as those mentioned earlier (BESS, BBS, CMBS), ${ }^{13}$ as well as Functional Gait Analysis (FGA), Clinical Test of Sensory Interaction in Balance (CTSIB), miniBESSTest, and Romberg (and its variations), ${ }^{20}$ which have been validated for multiple population types. To advance the clinical utility of COM sway as an outcome measure, future research should focus on what functional activities are negatively affected by decreased control of postural sway, and what norms and cutoff scores determine dysfunction. In current clinical practice, the authors recommend including dynamic balance activities that challenge ML control of the COM, though future research is needed to determine whether this deficit translates to dysfunction or risk of reinjury.

One study compared athletes and non-athletes, and significant differences were found in ML sway variables suggesting that repeated sub-concussive blows due to certain types of athletic participation may produce a measurable consequence for controlling the whole body COM during gait. ${ }^{11}$ However, this assumption cannot be confirmed based on the studies reviewed. While this is an intriguing line of thinking, more research would be needed to determine the true factors contributing to COM displacement changes in athletes compared to non-athletes, both in the presence of concussion and those who have sustained repeated sub-concussive impacts which are typical in athletics. Without the results of such research, COM may not be a useful measure in determining presence of dynamic gait deficits in athletes who have sustained concussion, since they may display significant deficits either way. This line of research could be expanded to help establish norms for COM differences in athletic versus non-athletic populations, enhancing the generalizability of a clinical concussion treatment protocol.

The addition of a cognitive component to a dynamic task exposes persistent postural control deficits in subjects with subacute (post-28 days) to chronic concussion in both ML$\mathrm{COM}^{3,4,6,11,14,15}$ and AP-COM $3,6,11$ directions. There is currently no validated clinical outcome measure for the assessment of dynamic postural control when comparing singleand dual-task conditions for the concussed population. While neuropsychological testing is considered the standard for diagnosis and reassessment of concussion, and static balance assessment tools are commonly used in clinical practice to show progress, neither of these incorporate dynamic movements with cognitive tasks. ${ }^{4,6,18}$ As a result, neuropsychological testing and static balance assessments may not capture lingering motor impairments. Returning to both daily function and sport requires the ability to balance while moving the body through space and completing various cognitive tasks, such as attention-switching, responding to environmental and verbal cues, and reacting to visual and verbal stimuli. The subtleties of concussion injuries often appear in these more complex tasks where COM variables prove to be most valuable. ${ }^{17}$ While no standardized COM assessment currently exists in routine clinical practice, adding a cognitive component to dynamic tasks could offer an adequate option to elucidate subtle impairments. More research needs to be conducted to determine at what point in the recovery timelines the addition of the dual-task 
condition would present an appropriate challenge. At present, subjective rating of symptom exacerbation following dynamic dual-task activities should keep patients safe and appropriately challenged without neglecting this aspect of their recovery.

A limited population of participants were available for analysis with all relevant studies reviewing athletes versus non-athletes, or concussed athletes versus healthy controls and a limited total age range. The lack of diversity in age and population can be attributed to a sample of convenience offered by the athletic and younger population with higher concussion incidence and easier access to study enrollment than the general population (student proximity to university labs). ${ }^{3,4,6,11,14,15}$ Despite the apparent limitation of the study population type/age, this narrow population does allow for increased internal validity for the athletic and adolescent/young adult population. Results of the reviewed studies demonstrate similar responses across trials using similar methods of assessment for COM and velocity. Bias assessment revealed good results with STROBE scores ranging $26.5 \pm 3.5$ of 34 indicating decreased risk of systematic error. In order to better serve the field of study, additional research should be done to identify effects on a greater range of subjects types/ages that would better exemplify the general population using a standardized protocol. At this time there is a lack of external validity of review search results due to the homogenous sample pool offered in current studies.

\section{CONCLUSIONS}

The results of this systematic review indicate COM may be a strong indicator of ongoing impairment after a concussion. Multiple COM measures were found to be abnormal in athletes following concussion long after their clearance to return to play. This result is often dependent on the utilization of a dual task condition or distraction from the gait task in order to increase the difficulty of the gait task and allow the deviations to present. While limits in technology available to the clinician may restrict regular evaluation of $\mathrm{COM}$ during gait after concussion, these barriers may be lowering.

\section{CONFLICT OF INTEREST}

None of the authors have a conflict of interest to report.

Submitted: December 10, 2020 CDT, Accepted: June 15, 2021

CDT 


\section{REFERENCES}

1. Fino PC, Peterka RJ, Hullar TE, et al. Assessment and rehabilitation of central sensory impairments for balance in mTBI using auditory biofeedback: a randomized clinical trial. BMC Neurol. 2017;17. doi:1 $\underline{0.1186 / \mathrm{s} 12883-017-0812-7}$

2. McCrory P, Meeuwisse W, Dvorak J, et al. Consensus statement on concussion in sport-the 5th international conference on concussion in sport held in Berlin, October 2016. Br J Sports Med. Published online April 26, 2017:bjsports-2017-097699. doi:10.11 36/bjsports-2017-097699

3. Catena RD, van Donkelaar P, Chou L-S. Different gait tasks distinguish immediate vs. long-term effects of concussion on balance control. J Neuroeng Rehabil. 2009;6:25. doi:10.1186/1743-0003-6-25

4. Doherty C, Zhao L, Ryan J, Komaba Y, Inomata A, Caulfield B. Concussion is associated with altered preparatory postural adjustments during gait initiation. Hum Mov Sci. 2017;52:160-169. doi:10.101 6/j.humov.2017.02.005

5. McCrory P, Meeuwisse WH, Aubry M, et al. Consensus statement on concussion in sport: the 4th International Conference on Concussion in Sport held in Zurich, November 2012. British Journal of Sports Medicine. 2013;47(5):250-258. doi:10.1136/bjsports-2 $\underline{013-092313}$

6. Howell DR, Osternig LR, Chou L-S. Return to activity after concussion affects dual-task gait balance control recovery. Medicine \& Science in Sports \& Exercise. 2015;47(4):673-680. doi:10.1249/MSS.000 $\underline{0000000000462}$

7. Broglio SP, Eckner JT, Surma T, Kutcher JS. Postconcussion cognitive declines and symptomatology are not related to concussion biomechanics in high school football players. Journal of Neurotrauma. 2011;28(10):2061-2068. doi:10.1089/neu.2011.1905

8. Kerr ZY, Zuckerman SL, Wasserman EB, et al. Factors associated with post-concussion syndrome in high school student-athletes. Journal of Science and Medicine in Sport. 2018;21(5):447-452. doi:10.1016/j.js ams.2017.08.025

9. Erdman W. Center of mass of the human body helps in analysis of balance and movement. $\mathrm{MOJ}$ Applied Bionics and Biomechanics. 2018;Volume 2(Issue 2). doi:10.15406/mojabb.2018.02.00057
10. Howell DR, Osternig LR, Chou L-S. Consistency and cost of dual-task gait balance measure in healthy adolescents and young adults. Gait Posture. 2016;49:176-180. doi:10.1016/i.gaitpost.2016.07.008

11. Parker TM, Osternig LR, van Donkelaar P, Chou L$\mathrm{S}$. Balance control during gait in athletes and nonathletes following concussion. Med Eng Phys. 2008;30(8):959-967. doi:10.1016/j.medengphy.2007.1 $\underline{2.006}$

12. von Elm E, Altman DG, Egger M, Pocock SJ, Gøtzsche PC, Vandenbroucke JP. Strengthening the reporting of observational studies in epidemiology (STROBE) statement: guidelines for reporting observational studies. BMJ. 2007;335(7624):806-808. doi:10.1136/bmj.39335.541782.AD

13. Downs SH, Black N. The feasibility of creating a checklist for the assessment of the methodological quality both of randomised and non-randomised studies of health care interventions. J Epidemiol Community Health. 1998;52(6):377-384. doi:10.1136/i ech.52.6.377

14. Fino PC. A preliminary study of longitudinal differences in local dynamic stability between recently concussed and healthy athletes during single and dual-task gait. J Biomech. 2016;49(9):1983-1988. doi:10.1016/j.jbiomech.2016.05.004

15. Howell DR, Osternig LR, Chou L-S. Adolescents Demonstrate Greater Gait Balance Control Deficits After Concussion Than Young Adults. The American Journal of Sports Medicine. 2015;43(3):625-632. doi:1 0.1177/0363546514560994

16. Ebell MH, Siwek J, Weiss BD, et al. Strength of recommendation taxonomy (SORT): a patientcentered approach to grading evidence in the medical literature. J Am Board Fam Pract. 2004;69(3):548.

17. Teyhen D. Concussion: physical therapy treatment after mild traumatic brain injury. J Orthop Sports Phys Ther. 2020;50(4):178-178. doi:10.2519/jospt.2020.050 $\underline{3}$

18. McCulloch KL, de Joya AL, Hays K, et al. Outcome measures for persons with moderate to severe traumatic brain injury: recommendations from the american physical therapy association academy of neurologic physical therapy tbi edge task force. $J$ Neurol Phys Ther. 2016;40(4):269-280. doi:10.1097/NP T.0000000000000145 
19. Bohannon RW, Wang Y-C. Four-meter gait speed: normative values and reliability determined for adults participating in the NIH Toolbox Study. Arch Phys Med Rehabil. 2019;100(3):509-513. doi:10.1016/j.apm r.2018.06.031
20. Parrington L, Jehu DA, Fino PC, et al. The sensor technology and rehabilitative timing (START) protocol: a randomized controlled trial for the rehabilitation of mild traumatic brain injury. Phys Ther. 2020;100(4):687-697. doi:10.1093/ptj/pzaa007 


\section{APPENDIX 1: SEARCH STRATEGY}

\section{PUBMED}

c(CCCCCC(CCCC(CC(C“gait”) OR “gait”[MeSH Terms]) OR "gait initiation") OR "gait initiation"[MeSH Terms]) OR "gait abnormality") OR "gait abnormality" [MeSH Terms]) OR "gait performance") OR "gait performance"[MeSH Terms]) $O R$ "gait change") OR "gait change" [MeSH Terms]) OR "gait alteration") OR "gait alteration"[MeSH Terms]) OR "gait coordination") OR "gait coordination"[MeSH Terms]) OR "gait deviation") OR "gait deviation"[MeSH Terms]) OR "gait decline") OR "gait decline"[MeSH Terms]) OR "gait degradation") OR "gait degradation" [MeSH Terms] and $(C(C C C(C C(C(C$ “concussion" [MeSH Terms]) OR "concussion") OR "mild traumatic brain injury"[MeSH Terms]) OR "mild traumatic brain injury") OR "brain concussion" [MeSH Terms]) OR "brain concussion") OR "post-concussion syndrome"[MeSH Terms]) OR "post-concussion syndrome”) OR “mTBI"[MeSH Terms) OR “mTBI”) 